SECTION D: LOOKING FORWARD 


\title{
What Do We (Think We) Know About Formulaic Language? An Evaluation of the Current State of Play
}

\begin{abstract}
Alison Wray
This article briefly summarizes key developments in formulaic language research over the past 5 years, before exploring certain assumptions typically made, regarding the coherence of formulaicity as a phenomenon, the significance of frequency as a property, and the location of subtypes of formulaic language along various continua. It is argued that we do not yet have the full measure of how different features associated with formulaicity fit together. The challenge lies in reconciling the range of evidence types within an explanation that is rooted not only in usage itself, but in the underlying motivations that determine usage.
\end{abstract}

Now is a good time to take stock of formulaic language research. It is nearly 30 years since Pawley and Syder (1983) asked how native speakers successfully select the subset of grammatical constructions that are also idiomatic and produce language so fluently. Their answer was that a key aspect of nativelike linguistic knowledge is the mastery of many multiword sentences and partly lexicalized sentence stems, easily selected and easily chained to create fluent idiomatic output. Five years later, Sinclair (1987) proposed that when we process language we apply the idiom principle before the open choice principle-that is, we look for opportunities to map form to meaning at the multiword level if we can and break wordstrings down only if necessary. In the same year, Van Lancker (1987) published her excellent review of patterns of formulaic language in aphasia, raising the question of how the way we learn and use language might influence what remains after brain damage.

Ten years ago, I proposed that a single, fairly simple principle underlies formulaic language across its range of forms and domains: It is a linguistic solution to the problem of how to promote our own survival interests (Wray, 2002). Humans, being psychologically and socially complex, are unable fully to meet their emotional, mental, and physical needs without involving others. One effective tool for drawing others into behaviors beneficial to us is to employ wordstrings that are in current use in our community. They enable us socially 
to align ourselves with others (I am like you because I talk like you, so you will want to help me), and as a way of minimizing the risk of misunderstanding, since wordstrings or partly lexicalized frames that have their own semantic entry require less decoding.

As I shall briefly outline here, research activity around formulaic language seems to have increased considerably in the past decade. And within the body of the most recent research (much of which is reviewed in other articles in this volume), I perceive a significant shift in focus and emphasis, in which new kinds of questions are either directly posed or indirectly emerging. I shall examine the significance of these new trends in relation to what we assume and believe about formulaic language. The overall thrust of my exploration entails problematizing some of our basic assumptions and ground rules at the interface of different types of evidence. Formulaicity is an inherently complex phenomenon. My question is, how much additional complexity arises from the way we are conceptualizing it?

Before entering this discussion, we need to take a step back and consider the general patterns into which the recent research into formulaic language falls, so as to understand what sorts of claims might be affected by the assumptions I will be challenging.

\section{THE SCOPE OF RECENT FORMULAIC LANGUAGE}

There has long been an interest in formulaic language across a number of different domains of enquiry, including psycholinguistics, discourse analysis, phraseology, historical linguistics, corpus linguistics, grammar, first language (L1) acquisition, second language (L2) acquisition, clinical linguistics, computational linguistics, and others (see Wray, 2002). But in the past 10 years or so, something about formulaicity as a property of language has captured researchers' imagination, and there seems to have been an explosion of activity. One sign of it is the symposia and conferences organized around the theme, most notably the phraseology conferences (and their resulting volumes) in Basel in 2004 (Häcki Buhofer \& Burger, 2006, 2007) and in Louvain-la-Neuve in 2005 (Granger \& Meunier, 2008; Meunier \& Granger, 2008); the Wisconsin-Milwaukee Symposium on Formulaic Language in 2007 (Corrigan, Moravcsik, Ouali, \& Wheatley, 2009b, 2009c); the biennial international postgraduate conferences of the Formulaic Language Research Network (FLaRN), most recently in Paderborn in 2010 and Tilburg in 2012; and the first national Chinese conference on formulaic language in Beijing in 2009. We can identify six main strands in current research activity addressing the individual questions below.

\section{How Can the Patterns of Formulaic Sequences Best Be Categorized?}

With corpus methods the dominant approach to examining this question, there is an impressive range of recent descriptive (e.g., Biber, 2009; Biber \& Barbieri, 2007) and explanatory studies. The latter aim to characterize observed patterns of words in terms of underlying schemata of some sort, of which the 
observed instances are plausible examples. The dominant approach in such schema-building is what is called usage-based. Usage-based grammatical models "see grammar as a network built up from the categorized instances of language use" (Beckner et al., 2009, p.5) and thus interface effectively with the corpusbased methods for identifying examples. Construction grammar is a particularly powerful way of capturing key features of formulaic language, because it recognizes meaning as able to reside within grammatical frames as well as within individual lexical items (see later section). (For extensive coverage of the latest ideas in construction grammar, see Trousdale \& Hoffman, 2012). There is also increased interest in the semantic prosody of wordstrings (e.g., Culpeper, 2010; Ellis \& Frey, 2009; Ellis, Frey, \& Jalkanen, 2009; Wierzbicka, 2009), and in new and more sophisticated ways to capture the essence of collocation (Cheng, Greaves, Sinclair, \& Warren, 2009). Some of the issues raised in these works are discussed later in this article.

\section{What Do Native Speakers Know About Formulaic Sequences and How Do They Know It?}

Again, usage-based models make a major contribution to answering this question, offering evidence for how children's natural exposure to language input could result in sensitivity to idiomaticity, as a consequence of frequency of exposure to patterns (e.g., Abbot-Smith \& Tomasello, 2006; Bannard \& Lieven, 2009). The argument (Wray, 2002, 2008) that frequency is not enough to explain this knowledge (discussed later) is partly addressed by taking into account role of attention, noticing, and saliency (Beckner et al., 2009; Dominey \& Dodane, 2004; Ellis, 2006; Huang, 2009; Kurumada, 2009; Merritt, DeLosh, \& McDaniel, 2006; Perruchet \& Peereman, 2004; Wray \& Fitzpatrick, 2008).

\section{How Are Formulaic Sequences Processed?}

Earlier assertions regarding the holistic processing of formulaic language (for an overview, see Wray, 2002) have become increasingly anchored in neurological evidence. A range of investigations confirm that formulaic sequences (or at least some types of them-see later discussion) do seem to have a privileged processing status. Reaction time tasks (e.g., Conklin \& Schmitt, 2008; Jiang \& Nekrasova, 2007; Libben \& Titone, 2008), self-paced reading (e.g., Tremblay, Derwing, Libben, \& Westbury, 2011), and controlled recall (Tremblay \& Baayen, 2010) are now often combined with physical measures such as eye gaze (e.g., Millar, 2011; Siyanova-Chanturia, Conklin, \& Schmitt, 2011; Siyanova-Chanturia, Conklin, \& van Heuven, 2011), EEG recordings (e.g., Tremblay \& Baayen, 2010), or MEG measurements (e.g. Cappelle, Shtyrov, \& Pulvermüller, 2010). The proposal that fast-processing leads to changes in pronunciation (for a review, see Lin, 2010) has also led to explorations of ways to extract formulaic sequences automatically from spoken corpora (e.g., Strik, Hulsbosch, \& Cucchiarini, 2010).

There nevertheless remain important issues to address. One is the question of whether a processing advantage in terms of speed indicates holistic storage or simply the faster mapping of components-and indeed whether these are really 
two different things or just different ways of conceptualizing the same thing. The notion of holistic storage could be viewed as a device for talking about linguistic units that are ring-fenced for speedy processing-at the level of articulation, this must presumably be the case. On the other hand, there is potentially a different quality to holistic storage and access. First, it could entail the synchronous access of all components-as Tremblay and Baayen (2010) proposed as the best explanation for their results. Second, it could entail accessing (albeit in sequence) larger base components, through a direct mapping from the meaning of the entire expression to the phonological form (of those parts that are reliably fixed-as construction models might favor). Third, in the case of wordstrings that have become fused through repeated use, it could entail the creation of a new access pathway that bypasses the original componential route-as the extensive neurological research into automatic processing indicates. Hélie and Cousineau (2011) explored a range of evidence for which parts of the brain are involved in these processes, including the regions responsible for learning novel behaviors, and the transfer of control from one brain area to another once the action is automatic (see also Graybiel, 2008).

There remains for the present a significant gulf between the fine-grained observations of most neuroscientists, whose experimental tasks tend to be very simple compared with the comprehension and production of real language, and the language-driven investigations that open a more opaque window onto neurological processes. With new technologies, and ever increasing opportunities for interdisciplinary collaboration, we can hope in future to see more research that directly investigates language in use from the experimental neurological perspective.

\section{What Effect Do Formulaic Sequences Have on the Shape of Languages?}

At one level this question underpins the entire development of interest in formulaic language. Human languages without formulaic sequences would, we assume, lack idiomaticity, a considerable measure of the predictability that foregrounds what is most useful, and many layers of subtlety associated with how speakers and hearers apply the components of the language to real situations. In that sense, we have long been saying that formulaicity shapes languages.

However, formulaicity seems to exercise its own dynamic force on the shape of languages, as most powerfully exemplified in the assertion that it is the cause of the emergence of grammar (Booij, 2010; Bybee, 2003; Bybee \& Cacoullos, 2009). The proposal is that when content words with their own discrete meanings are located in strings that are used often, they can undergo changes in pronunciation that weaken their indexation back to the isolated form. Over time, they become associated with a meaning that derives more holistically from the string as a whole, so that they are perceived to have a grammatical role. Beckner et al. (2009) concisely illustrated the process with be going to, which only a few centuries ago centrally entailed a meaning of physical movement, with the meaning of future intention only implied.

Grammaticization is a bottleneck whereby processing a wordstring holistically (or at least repeatedly and very fast) reduces the user's awareness of the 
discrete components, but yet later does not prevent the reanalysis of the whole into (a new set of) parts. Peters (2009) developed this theme further in the context of first language acquisition, noting that since the contents of formulaic sequences are often already grammaticized when children encounter them, part of the child's job is to "recover ... embedded morphemes and grammar ... [in] a kind of reverse of grammaticization" (p. 403).

The processes revealed through research into grammaticization are tantalizing, not least in inevitably tending to rely on post hoc evidence. Much more difficult-though perhaps not impossible given modern corpora-is observing changes while they are happening and exploring such questions as what contributes to the establishment of the threshold at which something becomes reanalyzed: If there were a uniform potential for leakage out of a fossilizing wordstring, then the older meaning would presumably continue to reestablish itself. Humans' capacity to tolerate alternative, and often effectively interchangeable, lexical and grammatical meanings (e.g., he's tired meaning he is in a state of tiredness and he has become tired) further invites consideration of how we can reliably interpret data during the period of transition from a lexical to a grammatical meaning.

Formulaic language is implicated in language change in other types of study too. For instance, Lancioni (2009) suggested that the forms of reconstructed Classical Arabic were distorted through the use of highly formulaic pre-Islamic texts (poetic material from the oral tradition) as a resource to supplement the limited content of the Quran.

\section{How Do Formulaic Sequences Impact on Second/Foreign Language Learning?}

A set of related questions can be posed: What patterns of formulaic sequences are known or not known by postchildhood language learners? How can the learning of them be improved? Which ones should be taught? Without question, the greatest amount of empirical research activity into formulaic sequences over the past few years has been in the domain of postchildhood L2 and foreign language learning. The reports, exemplified by many of the articles in the edited collections of Granger and Meunier (2008), Meunier and Granger (2008), Corrigan et al. (2009b, 2009c), and Wood (2010), and often drawing on extensive learner corpora, reveal that learners tend to have a small inventory of formulaic sequences that they overuse and often have limited sensitivity to register differences (see other articles in this volume). Research has addressed how attending to formulaic sequences can improve nativelikeness (Boers, Eyckmans, Kappel, Stengers, \& Demecheleer, 2006; Gardner \& Davies, 2007; Lindstromberg $\&$ Boers, 2008; Rott, 2009), the potential positive and negative role of deliberate memorization (Ding, 2007; Qi \& Ding, 2011; Wray \& Fitzpatrick, 2008; Wray \& Pegg, 2009), and rigorous approaches to identifying and teaching the most appropriate wordstrings (e.g., Erman, 2009; Liu, 2010; Simpson-Vlach \& Ellis, 2010).

One question that is rarely addressed head on is this: As native speakers of our L1, we are evidently very tuned into the value of using multiword strings reliably to express common meanings and achieve key interactional functions. Why then 
do we not, as taught L2 learners, make a beeline for every opportunity to identify mappings at the multiword level? My proposal (Wray, 2002, 2008) was that adult learners need a sense of control over the language-perhaps largely as a result of the culture of education in general, and the expectations, assumptions, and requirements of language teaching in particular-but it remains puzzling why any learner driven by pragmatism is not able to override this to a greater extent than seems to be the case, so as to approach language learning more holistically, like the Papuan and New Britain learners described by Thurman and Laycock (see Wray, 2008; Wray \& Grace, 2007).

In short, we have an increasing body of evidence that instructed L2 learners have an impoverished stock of formulaic expressions, and some indications from psycholinguistic and neurological measurements that aspects of the processing are different in L2 learners (e.g., Ellis, Simpson-Vlach, \& Maynard, 2008; SiyanovaChanturia, Conklin, \& Schmitt, 2011; Tremblay \& Baayen, 2010; Tremblay et al., 2011). What we lack still is firm evidence about why. The role of noticing and salience offers some pointers (see discussion later in this article), but I still perceive a missing link regarding why learners do not feel more empowered to harvest L2 input in larger chunks in the pursuit of painless routes to effective communication.

\section{What Effect Do Formulaic Sequences Have on the Shape of Our Interaction?}

In the context of academic writing, Kerz and Haas (2009) proposed that "the relatively high standardization of the academic way of representing facts" leads to "a reduction in the number of linguistic constructions used for realizations of contents typical of academic texts" (p. 98). Over time, they suggest, researchers learn to model their research activity around the accepted shape of the discourse. Wray and Grace (2007) propose that language forms stretch and retract in response to the behavior of a community of speakers-particularly how they interact with outsiders. Formulaic language marks insider status, protecting the identity of linguistic groups, but forms are regularized to increase transparency if the exclusion of outsiders becomes socially or economically undesirable. In this way, the amount and impenetrability of formulaic material in a language both reflects and influences the amount of interaction the speakers have with outsiders, particularly where there is an option to use a lingua franca instead.

Descriptions of formulaicity gain new power when one asks how one might seek to manipulate conditions to achieve a more favorable use or knowledge of language. Work by Davis and colleagues (Davis, 2006, 2007; Davis \& Maclagan, 2007, 2010), supplemented recently by some of my own (Lindholm \& Wray, 2011; Wray, 2010, 2011) explores how formulaic sequences can variously diminish or enhance communication by and with people with Alzheimer's disease (AD). The tendency of people with $\mathrm{AD}$ to repeat information, often in the same or a similar form time after time, can easily elicit a negative response from carers, who may then adopt their own set of formulaic responses as a means of distancing themselves emotionally from this stressful and potentially hurtful situation. The challenge, addressed by Davis's team and in the practical interventions of Clegg (2010), is to use formulaic language as a tool for opening up communication 
rather than closing it down, thus supporting not only the people with $\mathrm{AD}$ but also their caregivers in achieving a more satisfactory and rewarding level of interaction.

In a quite different sphere, Gruber (2009) showed how defendants in court can come across as insincere when they use formulaic expressions of regret, so that "more creative, less formulaic utterances might better serve defendants' communicative goals at sentencing" (p. 599). Gruber cited a number of previous studies in other settings that have also demonstrated "a palpable link in American culture between the perception of more creative language and speaker sincerity in the performance of expressive speech acts" (p. 600).

So far, so good. There has been plenty of research activity, and as a result we are making good progress in building up a body of reliable knowledge about formulaic language. Aren't we?

\section{HOW MANY ELEPHANTS?}

There is enough contrast in the research already described for it to be evident that different researchers are not all talking about precisely the same thing. What is less clear is what this observation signifies. In the preface to their twin edited volumes, Corrigan, Moravcsik, Ouali, and Wheatley (2009a) grappled with the unity of formulaic language. Having offered an answer to the question "What are formulae?", they concede that "the formulae discussed in the papers of [these] book[s] actually vary in how closely they conform to the prototypes described above" (p. xiv). Granger \& Meunier (2008; also Meunier \& Granger, 2008) faced a similar challenge in introducing the many faces of phraseology.

Formulaicity may be the lens through which disparate pursuits make more collective sense. Alternatively, we may simply be papering over cracks-even chasms-between distinct endeavors. It could even be that, in some domains at least, there has not been an increase in research activity at all, only a convergence of what was previously undertaken in different places under different headings, made one by the assembly of researchers at particular conferences and within edited collections. If so, the interest in a common topic may be no deeper than the (precipitate) adoption of a common terminology.

This article is too short to explore every aspect of this issue, so I will go straight to what I perceive to be the heart of the matter-the ways in which the empirical evidence from studies of how the brain processes language, and from large corpus studies, are feeding into theoretical models of (aspects of) formulaic language. It is common for researchers across the wider range of empirical studies to hook their accounts onto key claims from these discussions, sometimes in a rather piecemeal or superficial way. By drawing attention to the central challenges for theory (and the opportunities-for I do not mean to level undue criticism at the present work, only to indicate where it needs to go next), I hope to encourage the wider community of researchers to consider more critically the relevance and implications of any claims and models they adopt from other domains, particularly if they are stripped of their detail and context in the process. 


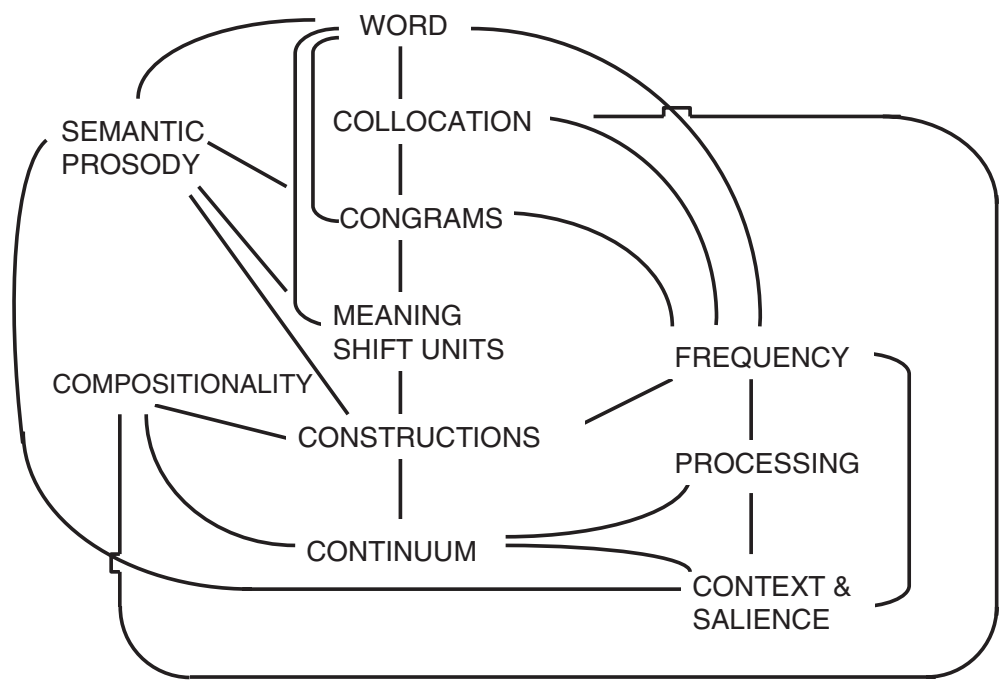

Fig. 1. The complex discussion space of current research into formulaic language.

In the course of undertaking the reading for this article, I examined how recent published studies on formulaic language were explicitly or implicitly conceptualizing the relationship between certain features typically associated with formulaicity. I wanted to understand how researchers with different priorities and approaches were dividing up, and prioritizing and deprioritizing aspects of, the so-called discussion space in which our assembled accounts are located. In particular, I was interested in how researchers made links between concepts in their discussion-what aspects or realizations of formulaic language did they refer to when describing or explaining their primary focus of interest? It was not a scientific trawl, and my purpose in presenting it here is purely illustrative.

The diagram I came up with (Figure 1) is alarmingly complicated. ${ }^{1,2}$ The lines in Figure 1 join the features that commentators have linked in their narrative or study design. In some cases the links are empirically based-for instance, when collocations are defined in terms of an aspect of the frequency of their co-occurrence. But in other cases, the links are inferred by authors on the basis of other evidence or are simply assumptions, and this is potentially problematic. Often a link is appropriate for some types of formulaic sequence but not (or not demonstrably) so for others. For instance, it is often asserted that formulaic sequences are located on a continuum, but continua can be based on different dimensions of variation that are not evidently directly related (e.g., semantic transparency, formality, frequency) as discussed later.

As with any such diagram, much may be learned from what is not linked. However, we need to consider under what circumstances features that are not directly linked can be viewed as linked via another feature. For instance, if one (type of) researcher links frequency and context/salience, and another links frequency and collocation, can we infer that collocation and context/salience are linked? The answer depends on a number of considerations regarding the 
relationships between the features. But it also will depend on whether frequency is really the same thing in both cases. Inherent, and inevitable, constraints on the types of example that can be used in particular research designs are one impediment to certainty about this. Another, arguably more tractable, is precision in the definition of key terms-something that requires not just general care and thoroughness, but also the kind of circumspection only possible from knowing how others, with very different research interests and foci, might want to make links across domains.

To put all of this another way, we can rather easily assume that formulaic language is like the elephant differently described by blind men with access to different parts of its huge mass. We may imagine that in due course our work will join up and we will grasp the nature of the whole beast. But the point of the metaphor is that the blind men don't know if they are in fact describing aspects of the same thing, because they can't see the elephant. And we, for the moment at least, cannot necessarily assume that there is a single phenomenon at the heart of our different activities, or if there is, that there are not also a few small rodents skulking about in the room too, confusing the description of the elephant and, perhaps, also influencing how it behaves. We can describe what we find, and call it formulaic language. But the elephant in the room is that we do not know if there is just one elephant in the room.

In the following sections I home in on some subparts of the complex space depicted in Figure 1, to attempt to tease apart what we really know from what we perhaps only believe we know. I have selected two groups of linked concepts from the diagram. These particular sets enable me to make some observations about our current knowledge, approaches, and assumptions, which may be of value in navigating the often confusing claims in formulaic language research.

\section{Continua, Processing, Frequency, and Salience}

Should we construe an expression as either formulaic or nonformulaic? Or are there degrees of formulaicity, with expressions located at any point along a continuum from entirely formulaic to entirely nonformulaic? The dual processing explanations offered by Van Lancker (1987; Van Lancker Sidtis, 2009), Sinclair (1987, 1991), and others, including in my own earlier work (e.g., Wray, 1999, 2000, 2002; Wray \& Perkins, 2000), strongly suggest a clear difference in kind between formulaic and nonformulaic processing, and this view is supported by some of the accounts of neurological pathways, as mentioned earlier in this article. On the other hand, other kinds of evidence, including frequency data, are much more in keeping with a continuum, and most formulaic sequences themselves have properties that seem to locate them somewhere between two extremes: While some formulaic sequences are entirely impenetrable (e.g., hocus pocus, by and large) and others entirely transparent (e.g., have a nice day), many partly map onto a relevant meaning (e.g., all of a sudden) or are literally obscure but can be mapped word by word onto their meaning at a metaphorical level (e.g., spill the beans).

A problem for our research is that, in order to establish answers to specific empirical questions, we need clear examples of formulaic and nonformulaic 
wordstrings. But even if we were comfortable that language users store the same items formulaically-which psycholinguistically motivated explanations will not guarantee-how safe can our assumptions be about what observations based on extreme types tell us about other kinds of examples? The challenge can be illustrated using the study by Conklin and Schmitt (2008), who asked, "Are formulaic sequences read more quickly than equivalent non-formulaic sequences?" (p. 80). Their experiment compared reading speeds for wordstrings that can have an idiomatic or literal reading, (e.g., take the bull by the horns). They located the wordstrings in contexts that directed the reader to one or other interpretation and found that the idiom interpretation was read more quickly.

But which other kinds of formulaic sequences can we assume this finding also applies to, and why? We can infer from their discussion that they see idioms as a reliable type of formulaic language, able to provide evidence relevant to a wider range of types. However, since idioms have holistic meanings that require their own semantic entry, perhaps this is why they are processed faster. We can assume, at least, that it is not on account of frequency, since true idioms tend not to be all that frequent (Moon, 1998).

Yet frequency evidently does play a role in processing, as Ellis's review (this volume) amply attests. Tremblay et al. (2011) found that sentences containing lexical bundles, such as in the middle of the, were processed faster and were more accurately recalled than matched sentences containing less frequent strings, such as in the front of the. In another investigation by the same team, Tremblay and Baayen (2010) showed participants blocks of six four-word strings of varying frequency in the British National Corpus, and then asked them to recall them as accurately as possible. They found a frequency effect and, by virtue of electroencephalograph (EEG) measurements, concluded that "phrasal and non-phrasal four-word sequences leave memory traces in the brain" (p. 170). They suggest that the loci of activation peaks and the speed of activation were consistent with holistic recognition for the most frequent strings.

So, both infrequent idioms and frequent lexical bundles seem to have some sort of processing advantage. Neither a continuum model of formulaicity that is based only on compositionality nor one based only on frequency is adequate to explain both. Are there two continua? If so, how do they relate to each other? If they intersect (as illustrated in Figure 2), we can predict that frequent noncompositional wordstrings (such as the names of prominent people) are fastprocessed, while infrequent, compositional wordstrings (as classically used as the control stimuli in experiments on both lexical bundles and idioms) are not. However, new questions also arise.

\section{Unpacking the Continua}

In Figure 2, we should anticipate that commonly used proper names are processed faster than either lexical bundles or idioms, since they benefit from both frequency and noncompositionality effects. I am not aware of research into this question, though it could be easily done. There is also the question of what lies partway along each continuum. What should we predict about fairly frequent or fairly compositional wordstrings? Are they processed fairly fast? Do both continua contribute at an equal rate to the processing speed? Alternatively, if 


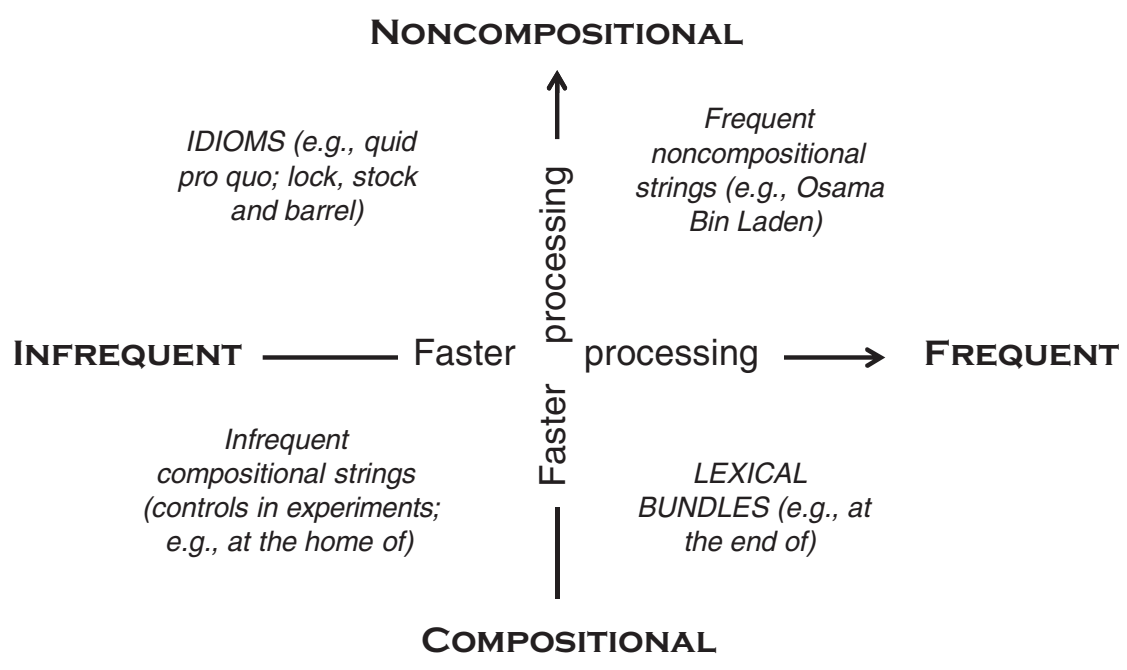

Fig. 2. Fast (or holistic) processing on two axes.

frequent use results in a new processing route in the brain (Hélie \& Cousineau, 2011), can we observe the buildup to reaching that threshold and a change in response behavior once the threshold is crossed?

A secondary question, easily missed by those whose own work does not involve frequency measures but who are tempted to adopt the idea that frequency is a (or the) significant variable in formulaicity, is how frequency itself is to be defined in the context of fast-processing. Ellis et al. (2008) found that the processing speed of native speakers was more sensitive to the mutual information (MI) score of the words in a string than to the raw frequency of the string as a whole. ${ }^{3}$ The implication is that MI is a more sophisticated index of a user's capacity to predict what comes next in a text than raw frequency is. But they found it was not as influential in nonnative speakers as native speakers. What explains the difference? It could be the reduced quantity of exposure that nonnative speakers have had to texts, or it could be an interacting variable, such as assumptions brought to the interpretation of an L2 on the basis of what is known about the L1 (Beckner et al., 2009), that might influence salience, as discussed later.

\section{Interacting Continua}

Figure 2 depicts infrequent, compositional wordstrings as not being formulaic, justifying their suitability as controls in experiments. Given the consistency in contrasts between such controls and the items identified as formulaic, it would be difficult to argue that it is wrong to use such items for the purpose. Nor is it really a problem if some such items are in fact formulaic for a given participant, which they might be, since we all have our own inventories. For instance, at the end of the war, used as a control by Siyanova et al. (2011), might happen to be the title of a play one took part in at school. Researchers can accept such variation 
as noise. It will reduce the overall contrast between the test and control item sets, and thus help strengthen confidence in a significant finding of difference.

The problem, if there is one, arises if we become aware that we are dealing with something more systematic-organized noise. The intersection of the frequency and compositionality continua in Figure 2 isolates a quadrant of types that are not seen as formulaic (and thus predicted not to be fast-processed). But another intersecting continuum could subdivide that quadrant, so that only some of the examples are still seen as definitely nonformulaic. Another could subdivide it again. It is not just that each such division reduces the number of possible examples-it is that it forces judgments about the relative importance of different variables and creates challenges for how one is to track or control for them. For instance, knowing what is in an L2 learner's personal inventory of formulaic expressions is surely likely to be a crucial determinant of how they respond to stimuli, yet it is difficult to accommodate adequately in a research design. In a current study, Huw Bell and I are using formulaic expressions from the Regency period (ca. 1800), as employed by Georgette Heyer in her historical novels, to minimize the variable of previous knowledge so that we can research how learners and native speakers figure out the meaning of formulaic sequences they have never seen before (Bell \& Wray, 2011).

There are several other possible axes of variation to consider. Recent explications of how fluent and/or automatic language is processed (Graybiel, 2008; Paradis, 2009; Segalowitz, 2010) (continue to) distinguish between implicit and explicit learning, and procedural and declarative knowledge. Idioms might be subject to explicit learning (Grant \& Bauer, 2004), even in native speakers, since the nonalignment of form and meaning, combined with the rarity of occurrence, must certainly draw attention. What we would have here is privileged processing on account of salience. An idiom is salient because its form is strikingly associated with its encoded meaning, so that even though it is not frequent, it is easily recognized and retrieved (Huang, 2009). As Ellis and Simpson-Vlach (2009) observed:

Sequences such as on the other hand and at the same time are more psycholinguistically salient than sequences such as to do with the, or I think it was, even though their frequency profiles may put them on equivalent lists. (p. 64)

Nesi and Basturkmen (2006) contrasted frequency and salience:

Lexical bundles that occur with very high frequency across a range of texts are likely to be stored in memory as unanalyzed chunks, a particularly interesting consideration in view of the fact that bundles tend to bridge syntactic boundaries and do not generally have idiomatic meaning, and are therefore not very salient, either to the listener/reader or to the language researcher. (p. 286)

Some research has suggested that salience can outrank frequency effects in cognitive tasks. Merritt et al. (2006) found that in mixed lists of high and low 
frequency words, the latter were better recalled, because they "attract more attention" (p. 1615). Setting aside the difference between speed of recall and accuracy of recall for a moment, this implies that one could observe processing advantages for frequent items compared with less frequent ones if the latter are not salient, as well as for salient items that are not frequent, as Ellis (2006), particularly concerned with perceptual salience, suggested. So is there a continuum of salience? If so, it is not necessarily one on which examples can be permanently located, for salience can be created temporarily by the context too (Huang, 2009).

A further potential complication is raised by Ellis (2006), who suggested that function words embedded in fossilized wordstrings have low salience so that, even though they are of high frequency in themselves (and occur in high frequency strings), they are difficult to notice. It would be for this reason that L2 learners struggle with the fine morphological detail of a target language (see also Beckner et al., 2009). A study by Wray and Fitzpatrick (2008) supports this position. We explored the patterns observed in the inaccurate recall by L2 speakers of deliberately memorized sentences and proposed that deviations from the original can reflect unconscious judgments during memorization about what needs to be attended to. These judgments are based on an assessment of the likelihood that an underspecified memory can be reconstructed reliably, and they represent a legitimate strategy used also by native speakers, but one that will backfire for nonnative speakers if the risk assessment is based on receptive rather than productive knowledge.

The question of low salience in frequent strings raises a question regarding part of Tremblay and Baayen's (2010) study, described earlier. They asked participants to do a free recall task of lexical bundles of different frequencies: "Our main interest here was to determine whether the number of times a sequence would be correctly recalled varied as a function of whole-string frequency/probability" (p. 156). Only an exact replication was counted as correct, and the examples they give of what would be counted as incorrect all involve the omission or substitution of what, in Ellis's terms, would be low salience functors. It may be that this simply sliced their data without fundamentally affecting their results-a frequency effect for accuracy of recall. However, they themselves expressed surprise at this finding, on account of Merritt et al.'s (2006) work, just described, which invoked salience as a variable. It may therefore be of some significance if the items identified as fast-processed on account of frequency were the subset with least incidence of low salience.

A different kind of continuum was discussed by Wulff (in press) in relation to construction grammar. She contrasted idiomatization and delexicalization-that is, the extent to which a construction is fully lexicalized or has been abstracted out to contain gaps allowing a range of alternatives. She quickly encountered problems with the one-dimensional model and proposed that "the constructicon could be extended by a horizontal axis ... which cuts across the range of the vertical axis where fully lexically specified complex constructions are located" (p. 18). This approach raises an interesting issue. Bisecting one continuum in a specific place, even to accommodate another, potentially challenges the status of the first continuum-what falls immediately above and below that locus of the "fully lexically specified complex construction" (p. 18)? Are lexical realizations 
in constructions a hard enough fact to require a punctuated, rather than entirely gradual, continuum? Where on the continuum should we place constructions with optional gaps or the full lexicalization of, say, one or other of a small number of alternatives (as with I haven't the faintest/foggiest [idea]; Tucker, 1996)?

Wulff's account does not end with a two-way intersection. Noting that "different factors like lexical specification, semantic irregularity, syntactic irregularity, and cognitive entrenchment prevail at all levels of the constructicon in different shades of prominence and relative importance," she proposed that, since "any given (schematic) idiom can be characterized individually along every single factor," we must recognize "a 'multi-dimensional continuum' of differently formally and semantically irregular and cognitively entrenched expressions that ultimately blurs the boundaries of idiom types" (p. 7). A multidimensional continuum certainly has merit over a one-dimensional one with different types of property laid along it, as critically discussed in Wray (2002), but now our attention has been drawn to complex adaptive systems (Beckner et al., 2009; Larsen-Freeman \& Cameron, 2008) and we can perhaps escape from the limitations of linearity, other than where we are truly satisfied that enough of the path has been mapped.

In sum, we see in the research literature explicit or implicit assumptions about continua based on (at least) frequency (raw and MI), compositionality, salience, and abstraction, with various levels of assertion or implication about how the location of a wordstring upon them might influence how it is processed. The risk we run in designing classic bipolar experiments on a single axis is that we strip out too many other potential influences. It is not that experimental effects cannot be found-they can. But I'm not convinced they are always being found for the reasons we think. We may inadvertently be selecting from a smaller subset than we realize, controlling, by virtue of procedural convenience, for a variable we are not considering. It does not matter, necessarily, for the particular experiment in question, but it does matter when we attempt to generalize the claim beyond the specific examples selected for testing, because we do not have a full picture of where the lines are to be drawn.

And so far, we have barely touched on the question of communication-the meanings we want to make, and the subtle judgments we need to engage in, so as to make them effectively. When we stand at the bus stop, we do not jump on the number 7 bus, irrespective of its destination, just because it comes more frequently than the number 12 , because it is painted in a brighter color, because it goes via certain landmarks, or because it reminds us of journeys we have taken on other buses. In the same way, we say the things we want and need to say-sometimes things that are often said; sometimes things that are rarely said; sometimes things that are remarkable to ourselves or others; sometimes deliberately things that are not at all remarkable; sometimes things that could be easily interpreted by someone unfamiliar with the formulation; sometimes things that are impenetrable to all but an insider. Only once we have decided what is important to say, do some or all of these other factors play a role in how we say it. This may seem like a point too obvious to make, but it is all too easy, in the interests of replicable science, to set aside, albeit inadvertently, an adequate consideration of why the road less traveled exists at all. ${ }^{4}$ 


\section{Words, Collocations, Concgrams, Constructions, and Meaning Shift Units}

The preceding discussion of frequency takes on particular significance in the light of some recent attempts to (re)define just what the unit of interest to researchers is. I want to explore aspects of the intricacy of word as a concept in recent discussions, as it interfaces with accounts of collocational patterns, phraseology, constructions, semantic prosody, and idiomaticity. I will use as the pivot the relationship between claims in construction grammar and some ideas emerging from the development of Sinclair's unpublished work, as presented by Cheng et al. (2009) in the context of opportunities afforded by concgram analysis.

\section{Formulaicity and Constructions}

Formulaic language has become very productively associated with the new generation of grammatical theories that locate multiword strings at the center, rather than the periphery, of our linguistic experience (Ellis, 2008; Taylor, 2002). Cognitive, usage-driven grammatical models see patterns emerge from the evidence of input, with abstractions derived from that evidence, rather than being independently motivated by prespecified, innate linguistic knowledge (Croft \& Cruse, 2004). Construction grammar construes a language as realizations of templates capable of containing syntactic, lexical, phonological (including prosodic), semantic, and pragmatic information (Croft \& Cruse, 2004). The kinds of holistic information associated with formulaic language-from fully fixed expressions to lexically unpopulated frames-are so integrated in this conceptualization that, since "it's constructions all the way down" (Goldberg, 2006, p. 18), there is perhaps a sense in which it is also formulaicity all the way down. In other words, perhaps everything we say is formulaic at one level or another, from the single morpheme, through the range of typical formulaic expressions such as idioms and routines, into collocations, and even onto completely novel grammatical utterances that, although populated by unpredicted lexical items, fall into abstract frames that provide semantic associations between the individual words.

The effect of this possibility on how we think of formulaic language is curious. On the one hand, the idea that everything is built out of constructions is a very close alternative to conceptualizing formulaic expressions as (holistically managed) lexical entries. What we gain with construction grammar is the capacity to set aside any logically possible wordstrings that are not idiomatic-this is a very useful asset, because it solves the problem of overgeneration that has been the keenest test of grammatical theories over many decades (Kay, 2012). On the other hand, we may sense a flattening effect-a loss of perspective. "When everyone is somebody, then no one's anybody," observed a character in Gilbert \& Sullivan's The Gondoliers. What attracted our attention to formulaic language was that certain wordstrings stood out as more formulaic than others, even within the subset of those that are idiomatic.

Usage-based models most directly allow us to discriminate on the basis of level of abstraction-for instance, in construction grammar, how much of a 
construction is lexically fixed-and on the basis of frequency. Although frequency is sensitive to semantics, pragmatics, and cultural practice, there are things we wanted to know that require a different dimension of digging: why people with aphasia can produce some multiword strings and not others, why some idiomatic wordstrings are easier for L2 learners to master than others, and why some expressions are stronger markers of social identity than others. These considerations resonate with the earlier observation that frequency-based studies can easily miss taking full account of the social and psychological drivers of human linguistic behavior. Again, here, I am not intending to criticize the models for having the primary focus that they do, nor am I implying that their proponents are ignorant of or ambivalent toward these dynamics of language. It's just that this is all very complicated. Perhaps the image of an elephant should have been one of an octopus, which, each time you think you are starting to contain it, throws out another tentacle and grabs tight to a factor you had hoped to keep out of its reach.

\section{Concgrams and Meaning Shift Units}

Concgrams are "instances of co-occurring words irrespective of whether or not they are contiguous, and irrespective of whether or not they are in the same sequential order" (Cheng et al., 2009, p.237). Cheng et al. gave the following explanation:

[They] comprise all of the permutations of constituency variation, for example AB ("work hard") and A_B ("work very hard"), and positional variation, for example $\mathrm{AB}$ ("work hard") and BA ("hard work"), resulting from the co-occurrence of two or more words within a wide span of up to twelve words on either side of the "origin." (p. 238)

Cheng et al. asserted that "examining concgrams takes us closer to more fully appreciating and understanding the idiom principle" (p. 236), because it extends the scope of patterns beyond the more linear arrangements of n-gram lists.

Cheng et al. (2009) drew on ideas developed but not published by Sinclair, which move the focus away from recurrent patterns toward the uniqueness of each word combination. Sinclair proposed the meaning shift unit (MSU) as a means of thinking in new ways about collocations and lexical items, because "the co-selection of the constituents causes a shift in the ambient meaning" (Sinclair, quoted in Cheng et al., p. 237). This seems to echo Taylor's (2002) view that some measure of noncompositionality is the rule rather than the exception. ${ }^{5}$

The flexibility of concgrams has to be tempered by a means of managing the output of the searches, something that continues to require human judgment (W. Cheng, personal communication, July 2011) and entails sorting examples into those that do and do not belong together. Sinclair's approach, echoed in the analytic procedures applied by Cheng et al. (2009), is that there is a single canonical form of a word group (identified operationally by Cheng et al. as the most frequent, which might be a point for future discussion), from which variations arise with lesser and greater "degrees of turbulence" (p. 243). Cheng 
et al. illustrated the case with the co-occurrences of play and role and the considerations required for including within the play/role MSU set a string like the role he would play while excluding role playing exercises.

The assertion that words affect each other's meanings dates back most famously to Firth $(1957$, p. 11) and no doubt much further, but is frequently revisited by commentators struggling to navigate the inherent complexities of meaning within and between units of different sizes. For instance, Wulff (in press) proposed that compositionality can be measured on the basis of "the semantic similarity of the contexts of the construction compared with those of its component words" (p. 10). Wulff hypothesized, and empirically confirmed, that native speakers are sensitive to this measure. Meanwhile, Mollet, Wray, and Fitzpatrick (2011) examined ways of capturing how the collocates of one word are influenced by the presence or absence of another word in the co-text.

\section{Collocations and Frequency}

One link between discussions of collocation and discussions of frequency lies in Sinclair's doubt about the usefulness of counting word and collocate frequencies:

It is not the statistical tests in themselves which are problematic; the problem lies in not recognizing that when writers and speakers co-select words, they create a new meaning which makes other instances of the same individual words and other co-selections involving these same words irrelevant. (Cheng et al., 2009, p. 237)

That is, Sinclair placed the burden of meaning so firmly in the local (semantic) context that when a given word occurs with different collocates, it must be considered a homograph (Cheng et al., 2009). This position inevitably throws into grave question the usefulness of word as an operable concept in certain kinds of linguistic study.

\section{CONCLUSION}

Why does a continuum of frequency not explain formulaicity more neatly than it does? Why does it remain so extraordinarily difficult to work out where the word fits into a picture of language as an emergent product of usage? The former question is best addressed through the latter. We have seen in the preceding discussion how words persistently confound attempts fully to isolate them without loss of vital information. The attempt to isolate them at all, however, is premised on the assumption that doing so is to restore something lost. According to Beckner et al. (2009, p. 6), "articulatory patterns in speech indicate that as words co-occur in speech, they gradually come to be retrieved as chunks." I am not sure that is entirely true. Articulatory patterns certainly indicate that there are articulatory chunks, and that we are able to identify within them phonological approximations of individual words that we also know. We certainly can spot 
individual words within the chunk, and we can normally identify the individual words that, historically, have contributed to creating it. But that is all. It is a matter of separating out what happened once from what happens now.

To argue that "the English contracted forms (I'm, they'll) originate from the fusion of co-occurring forms" (Beckner et al., 2009, p. 6) is not a problem, but this historical process has turned them into words, albeit with complex meanings, that are encountered as units in use. First language research indicates that chunks of this sort are not broken down at once (Bannard \& Lieven, 2009; Peters, 2009), with some never broken down at all (Wray, 2002). There is no need to attribute to each individual user a stake in the process of chunking the words into strings even if they do end up realizing they can be unchunked. Nor does Bybee's (2003; Bybee \& Cacoullos, 2009) historically oriented account require or necessarily imply it. But there is sometimes a discernible dissonance regarding what is prefabricated, that is, already assembled when encountered, and what is made formulaic through awareness of the behavior of the constituent units:

Corpus analyses in fact verify that communication largely consists of prefabricated sequences, rather than an "open choice" among all available words ... Such patterns could only exist if speakers were registering instances of co-occurring words, and tracking the contexts in which certain patterns are used. (Beckner et al., 2009, p. 6)

Again, I am not sure this is true. I think such patterns could also exist if speakers were registering instances of the whole string, with a meaning, with only a gradually emerging awareness that the string could be broken down into (a full set of) components. I don't think you need to know if you are talking about a bare-faced lie or a bear-faced lie in order to know what one is, and if the spelling is immaterial because only the phonology matters, then it is not a matter of registering co-occurring words, only co-occurring sounds. Alternatively, we may imagine that individuals attribute instances of this expression to the frequency profile of one or the other word: bear or bare. Perhaps so, but not always, for there are instances where people sit on the fence, such as not knowing whether they should use a $/ \mathrm{k} /$ or $/ \mathrm{t} /$ in streets/streaks ahead and in off his own back/bat. In this article I have not been trying to nit-pick at what are very solid and wellthought-through developments in our understanding of formulaic sequences. My primary concern is the ease with which claims made in one domain are often adopted by those in another, without adequate recognition of the limitations of what we know. We need to be careful about generalizations until we can have more certainty about what an elephant looks like. As for the question of what a word is, there is plenty more scope to examine the powerful effect of our own acculturation into a literate, alphabetic world on what we think we are observing. Words are more elusive than they ought to be, particularly when one explores nonliterate cultures and languages written in characters (Wray, 2008), and we must not get distracted by white spaces on the page, particularly given the computer's reliance on them in corpus searches. If Sinclair is right, the units we need to be examining are less changeable than we have supposed at the level 
of lexical options, but more changeable in terms of their mutual arrangement: moths dancing round a candle-we rarely see exactly the same thing twice.

Yet of course, we are pattern spotters. We know that language learning and language knowledge are about extrapolation, not just listing. It would be more than bizarre to set aside the vast body of evidence that has been amassed about the regularities of language-regularities upon which our language use is evidently based. The point is, to hijack Goldberg's words yet again, it's complicated all the way down. ${ }^{6}$ The fact that we can go some way toward reducing language learning and knowledge to a set of relatively simple processes, give or take some noise, does not mean there is nothing else to explore or explain. We are meaning makers, we are interactors and manipulators - and we are creative, too. If we are sensitive to frequency and salience, if we can break things down and build things up, if we use large units and small units, that is part of the story, but context is more than just the words that collocate with other words. It is about who we are and how we use language to express our identity and manipulate our world.

\section{ACKNOWLEDGMENTS}

I am grateful to Nick Ellis, Tess Fitzpatrick, Aneta Pavlenko, Charlene Polio, Norman Segalowitz, Mike Wallace, and an anonymous reviewer for helpful comments on the drafts of this article.

\section{NOTES}

1 The terms included in the diagram are explained in the discussions later in the paper.

2 Of course, I am not the only one to notice that we have a complicated set of phenomena here. Beckner et al.'s (2009) position paper on language as a complex adaptive system is heavily influenced by observations directly pertaining to multiword constructions and, thus, formulaic language.

3 "Mutual information: A statistical measure that compares the probability of finding two items together to the probabilities of finding each item on its own" (Baker, Hardie, \& McEnery, 2006, p. 120).

4 "Dass Phraseologismen nicht nur Einheiten der Sprache sondern auch mit dem kulturellen System verbunden sind, ist jedoch eine alte Erkenntnis" (Häcki Buhofer, 2006, p. vii). [That formulaic expressions (phraseologisms) are not just units of language but also bound up with the cultural system has been long since understood].

5 The primary thrust of Taylor's point is that we cannot simply divide expressions into two groups, noncompositional and compositional. However, he stated, "Most expressions (I am tempted to say: all expressions), when interpreted in the context in which they are uttered, are non-compositional to some degree," (p. 550) which does seem similar to Sinclair's point.

6 Not, of course, Goldberg's words, originally: for it is turtles all the way down (see the start of chapter 1 in Stephen Hawking's A Brief History of Time).

\section{ANNOTATED BIBLIOGRAPHY}

Corrigan, R., Moravcsik, E. A., Ouali, H., \& Wheatley, K. M. (Eds.). (2009). Formulaic language: Vol. 1. Distribution and historical change and Vol. 2. Acquisition, loss, 
psychological reality, and functional explanations. Amsterdam, the Netherlands: John Benjamins.

An excellent collection of essays covering a broad range of topics, based on presentations at the Wisconsin-Milwaukee Symposium on Formulaic Language in 2007.

Granger, S., \& Meunier, F. (Eds.). (2008). Phraseology: An interdisciplinary perspective. Amsterdam, the Netherlands: John Benjamins.

A rich assembly of articles exploring the more theoretical end of formulaic language, with a strong flavor of European phraseology.

Meunier, F., \& Granger, S. (2008). Phraseology in foreign language learning and teaching. Amsterdam, the Netherlands: John Benjamins.

A useful resource for those with a particular interest in the L2 learner aspects of formulaic language.

Wray, A. (2008). Formulaic language: Pushing the boundaries. Oxford, UK: Oxford University Press.

Building on Wray (2002), this is an attempt to tease out issues arising from claims and assumptions about formulaic language, and to pursue the question of how everything fits together.

\section{REFERENCES}

Abbot-Smith, K., \& Tomasello, M. (2006). Exemplar-learning and schematization in a usage-based account of syntactic acquisition. Linguistic Review, 23, 275-290.

Baker, P., Hardie, A., \& McEnery, T. (2006). A glossary of corpus linguistics. Edinburgh, UK: Edinburgh University Press.

Bannard, C., \& Lieven, E. (2009). Repetition and reuse in child language learning. In R. Corrigan, E. A. Moravcsik, H. Ouali, \& K. M. Wheatley (Eds.), Formulaic language: Vol. 2. Acquisition, loss, psychological reality, and functional explanations (pp. 297-321). Amsterdam, the Netherlands: John Benjamins.

Beckner, C., Blythe, R., Bybee, J., Christiansen, M., Croft, W., Ellis, ... \& Schoenemann. (2009). Language is a complex adaptive system: Position paper. Language Learning, 59(Supp. 1), 1-26.

Bell, H., \& Wray, A. (2011, September). How do we decode opaque formulaic sequences? Paper presented at the BAAL Annual Conference, University of the West of England, Bristol, UK.

Biber, D. (2009). A corpus-driven approach to formulaic language in English. International Journal of Corpus Linguistics, 14, 275-311.

Biber, D., \& Barbieri, F. (2007). Lexical bundles in university and spoken and written registers. English for Specific Purposes, 26, 263-286.

Boers, F., Eyckmans, J., Kappel, J., Stengers, H., \& Demecheleer, M. (2006). Formulaic sequences and perceived oral proficiency: Putting a lexical approach to the test. Language Teaching Research, 10, 245-261.

Booij, G. (2010). Construction morphology. Oxford, UK: Oxford University Press.

Bybee, J. (2003). Mechanisms of change in grammaticization: The role of frequency. In B. Joseph \& R. Janda (Eds.), Handbook of historical linguistics (pp. 602-623). Oxford, UK: Blackwell.

Bybee, J., \& Cacoullos, R. T. (2009). The role of prefabs in grammaticization: How the particular and the general interact in language change. In R. Corrigan, E. A. Moravcsik, 
H. Ouali, \& K. M. Wheatley (Eds.), Formulaic language: Vol. 1. Distribution and historical change (pp. 187-217). Amsterdam, the Netherlands: John Benjamins.

Cappelle, B., Shtyrov, Y., \& Pulvermüller, F. (2010). Heating up or cooling up the brain? MEG evidence that phrasal verbs are lexical units. Brain and Language 115, 189-201.

Cheng, W., Greaves, C., Sinclair, J. M., \& Warren, M. (2009). Uncovering the extent of the phraseological tendency: Towards a systematic analysis of concgrams. Applied Linguistics, 30, 236-252.

Clegg, D. (Ed.). (2010). Tell Mrs. Mill her husband is still dead. Trebus Project. Retrieved from www.trebusprojects.org

Conklin, K., \& Schmitt, N. (2008). Formulaic sequences: Are they processed more quickly than nonformulaic language by native and nonnative speakers? Applied Linguistics, 29, 72-89.

Corrigan, R., Moravcsik, E. A., Ouali, H., \& Wheatley, K. M. (2009a). Introduction: Approaches to the study of formulae. In R. Corrigan, E. A. Moravcsik, H. Ouali, \& K. M. Wheatley (Eds.), Formulaic language: Vols. $1 \& 2$ (pp. xi-xxiv). Amsterdam, the Netherlands: John Benjamins.

Corrigan, R., Moravcsik, E. A., Ouali, H., \& Wheatley, K. M. (Eds.). (2009b). Formulaic language: Vol. 1. Distribution and historical change. Amsterdam, the Netherlands: John Benjamins.

Corrigan, R., Moravcsik, E. A., Ouali, H., \& Wheatley, K. M. (Eds.). (2009c). Formulaic language: Vol. 2. Acquisition, loss, psychological reality, and functional explanations. Amsterdam, the Netherlands: John Benjamins.

Croft, W., \& Cruse, D. A. (2004). Cognitive linguistics. Cambridge, UK: Cambridge University Press.

Culpeper, J. (2010). Conventionalised impoliteness formulae. Journal of Pragmatics, 42, $3232-3245$.

Davis, B. H. (2006). Culturally competent materials on communication and dementia. Charlotte, NC: University of North Carolina.

Davis, B. H. (2007). Culturally competent materials on communication and dementia: Year two. Charlotte, NC: University of North Carolina.

Davis, B. H., \& Maclagan, M. (2007, July). Formulaicity and fillers in Alzheimer's talk. Paper presented at the International Pragmatics Association Conference, Göteborg, Sweden.

Davis, B. H., \& Maclagan, M. (2010). Pauses, fillers, placeholders, and formulaicity in Alzheimer's discourse: Gluing relationships as impairment increases. In N. Amiridze, B. H. Davis, \& M. Maclagan (Eds.), Fillers, pauses, and placeholders (pp. 189-216). Amsterdam, the Netherlands: John Benjamins.

Ding, Y. (2007). Text memorization and imitation: The practices of successful Chinese learners of English. System, 35, 271-280.

Dominey, P. F., \& Dodane, C. (2004). Indeterminacy in language acquisition: The role of child directed speech and joint attention. Journal of Neurolinguistics, 17, 121-145.

Ellis, N. C. (2006). Selective attention and transfer phenomena in L2 acquisition: Contingency, cue competition, salience, interference, overshadowing, blocking, and perceptual learning. Applied Linguistics, 27, 164-194.

Ellis, N. C. (2008). Phraseology: The periphery and the heart of language. In F. Meunier \& S. Granger (Eds.), Phraseology in foreign language learning and teaching (pp. 1-13). Amsterdam, the Netherlands: John Benjamins.

Ellis, N. C., \& Frey, E. (2009). The psycholinguistic reality of collocation and semantic prosody (2): Affective priming. In R. Corrigan, E. A. Moravcsik, H. Ouali, \& K. M. Wheatley (Eds.), Formulaic language: Vol. 2. Acquisition, loss, psychological reality, and functional explanations (pp. 473-497). Amsterdam, the Netherlands: John Benjamins.

Ellis, N. C., Frey, E., \& Jalkanen, I. (2009). The psycholinguistic reality of collocation and semantic prosody (1): Lexical access. In U. Römer \& R. Schulze (Eds.), Exploring the lexis-grammar interface (pp. 89-114). Amsterdam, the Netherlands: John Benjamins.

Ellis, N. C., \& Simpson-Vlach, R. (2009). Formulaic language in native speakers: Triangulating psycholinguistics, corpus linguistics, and education. Corpus Linguistics and Linguistic Theory, 5, 61-78. 
Ellis, N. C., Simpson-Vlach, R., \& Maynard, C. (2008). Formulaic language in native and second language speakers: Psycholinguistics, corpus linguistics, and TESOL. TESOL Quarterly, 42, 375-396.

Erman, B. (2009). Formulaic language from the learner perspective: What the learner needs to know. In R. Corrigan, E. A. Moravcsik, H. Ouali, \& K. M. Wheatley (Eds.), Formulaic language: Vol. 2. Acquisition, loss, psychological reality, and functional explanations (pp. 323-346). Amsterdam, the Netherlands: John Benjamins.

Firth, J. R. (1957). Papers in Linguistics 1934-1951. London, UK: Oxford University Press.

Gardner, D., \& Davies, M. (2007). Pointing out frequent phrasal verbs: A corpus-based analysis. TESOL Quarterly, 41, 339-359.

Goldberg, A. (2006). Constructions at work: The nature of generalization in language. Oxford, UK: Oxford University Press.

Granger, S., \& Meunier, F. (Eds.). (2008). Phraseology: An interdisciplinary perspective. Amsterdam, the Netherlands: John Benjamins.

Grant, L., \& Bauer, L. (2004). Criteria for re-defining idioms: Are we barking up the wrong tree? Applied Linguistics, 25, 38-61.

Graybiel, A. M. (2008). Habits, rituals, and the evaluative brain. Annual Review of Neuroscience, $31,359-387$.

Gruber, M. C. (2009). Accepting responsibility at defendants' sentence hearings: No formulas for success. In R. Corrigan, E. A. Moravcsik, H. Ouali, \& K. M. Wheatley (Eds.), Formulaic language: Vol. 2. Acquisition, loss, psychological reality, and functional explanations (pp. 545-566). Amsterdam, the Netherlands: John Benjamins.

Häcki Buhofer, A. (2006). Vorwort [Foreword]. In A. Häcki Buhofer \& H. Burger (Eds.), Phraseologie in motion I (pp. i-xvi). Essen, Germany: Schneider Verlag Hohengehren $\mathrm{GmbH}$.

Häcki Buhofer, A., \& Burger, H. (Eds.). (2006). Phraseologie in motion I. Essen, Germany: Schneider Verlag Hohengehren GmbH.

Häcki Buhofer, A., \& Burger, H. (Eds.). (2007). Phraseologie in motion II. Essen, Germany: Schneider Verlag Hohengehren GmbH.

Hélie, S., \& Cousineau, D. (2011). The cognitive neuroscience of automaticity: Behavioral and brain signatures. Cognitive Sciences, 6, 25-43.

Huang, M. Z. (2009). Solving the riddle of metaphor: A salience-based model for metaphorical interpretation in a discourse context. In V. Evans \& S. Pourcel (Eds.), New directions in cognitive linguistics (pp.107-126). Amsterdam, the Netherlands: John Benjamins.

Jiang, N., \& Nekrasova, T. M. (2007). The processing of formulaic sequences by second language speakers. Modern Language Journal, 91, 433-445.

Kay, P. (2012). The limits of construction grammar. In G. Trousdale \& T. Hoffmann (Eds.), The Oxford handbook of construction grammar. Oxford, UK: Oxford University Press.

Kerz, E., \& Haas, F. (2009). The aim is to analyze NP: The function of prefabricated chunks in academic texts. In R. Corrigan, E. A. Moravcsik, H. Ouali, \& K. M. Wheatley (Eds.), Formulaic language: Vol. 1. Distribution and historical change (pp.97-115). Amsterdam, the Netherlands: John Benjamins.

Kurumada, C. (2009). The acquisition and development of the topic marker $w a$ in L1 Japanese. In R. Corrigan, E. A. Moravcsik, H. Ouali, \& K. M. Wheatley (Eds.), Formulaic language: Vol. 2. Acquisition, loss, psychological reality, and functional explanations (pp. 347-374). Amsterdam, the Netherlands: John Benjamins.

Lancioni, G. (2009). Formulaic models and formulaicity in classical and modern standard Arabic. In R. Corrigan, E. A. Moravcsik, H. Ouali, \& K. M. Wheatley (Eds.), Formulaic language: Vol. 1. Distribution and historical change (pp.219-238). Amsterdam, the Netherlands: John Benjamins.

Larsen-Freeman, D., \& Cameron, L. (2008). Complex systems and applied linguistics. Oxford, UK: Oxford University Press.

Libben, M. R., \& Titone, D. (2008). The multidetermined nature of idiom processing. Memory and Cognition, 36, 1103-1121. 
Lin, P. M. S. (2010). The phonology of formulaic sequences: A review. In D. Wood (Ed.), Perspectives on formulaic language: Acquisition and communication (pp. 174-193). London, UK: Continuum.

Lindholm, C., \& Wray, A. (2011). Proverbs and formulaic sequences in the language of elderly people with dementia. Dementia: The International Journal of Social Research and Practice, 10, 603-623

Lindstromberg, S., \& Boers, F. (2008). The mnemonic effect of noticing alliteration in lexical chunks. Applied Linguistics, 29, 200-222.

Liu, D. (2010). Going beyond patterns: Involving cognitive analysis in the learning of collocations. TESOL Quarterly, 44, 4-30.

Merritt, P. S., DeLosh, E. L., \& McDaniel, M. A. (2006). Effects of word frequency on individual-item and serial order retention: Tests of the order-encoding view. Memory and Cognition, 34, 1615-1628.

Meunier, F., \& Granger, S. (2008). Phraseology in foreign language learning and teaching. Amsterdam, the Netherlands: John Benjamins.

Millar, N. (2011). The processing of malformed formulaic language. Applied Linguistics, $32,129-148$.

Mollet, E., Wray, A., \& Fitzpatrick, T. (2011). Accessing second-order collocation through lexical co-occurrence networks. In T. Herbst, P. Uhrig, \& S. Schüller (Eds.), Chunks in corpus linguistics and cognitive linguistics: In honor of John Sinclair (pp. 87-121). Berlin, Germany: Mouton de Gruyter.

Moon, R. (1998). Fixed expressions and idioms in English. Oxford, UK: Clarendon Press.

Nesi, H., \& Basturkmen, H. (2006). Lexical bundles and discourse signaling in academic lectures. International Journal of Corpus Linguistics, 11, 283-304.

Paradis, M. (2009). Declarative and Procedural Determinants of Second Languages. Amsterdam, the Netherlands: John Benjamins.

Pawley, A., \& Syder, F. H. (1983). Two puzzles for linguistic theory: Nativelike selection and nativelike fluency. In J. C. Richards \& R. W. Schmidt (Eds.), Language and Communication. (pp. 191-226). New York, NY: Longman.

Perruchet, P., \& Peereman, R. (2004). The exploitation of distributional information in syllable processing. Journal of Neurolinguistics, 17, 97-119.

Peters, A. M. (2009). Connecting the dots to unpackage the language. In R. Corrigan, E. A. Moravcsik, H. Ouali, \& K. M. Wheatley (Eds.), Formulaic language: Vol. 2. Acquisition, loss, psychological reality, and functional explanations (pp.387-404). Amsterdam, the Netherlands: John Benjamins.

Qi, Y., \& Ding, Y. (2011). Use of formulaic sequences in monologues of Chinese EFL learners. System, 39, 164-174.

Rott, S. (2009). The effect of awareness-raising on the use of formulaic constructions. In R. Corrigan, E. A. Moravcsik, H. Ouali, \& K. M. Wheatley (Eds.), Formulaic language: Vol. 2. Acquisition, loss, psychological reality, and functional explanations (pp. 405-422). Amsterdam, the Netherlands: John Benjamins.

Segalowitz, N. (2010). Cognitive bases of second language fluency. New York, NY: Routledge.

Simpson-Vlach, R., \& Ellis, N. C. (2010). An academic formulas list: New methods in phraseology research. Applied Linguistics, 31, 487-512.

Sinclair, J. M. (1987). Collocation: A progress report. In R. Steele \& T. Threadgold (Eds.), Language topics: Essays in honour of Michael Halliday (pp.319-332). Amsterdam, the Netherlands: John Benjamins.

Sinclair, J. M. (1991). Corpus, concordance, collocation. Oxford, UK: Oxford University Press.

Siyanova-Chanturia, A., Conklin, K., \& Schmitt, N. (2011). Adding more fuel to the fire: An eye-tracking study of idiom processing by native and non-native speakers. Second Language Research. Advance online publication. doi: 10.1177/0267658310382068

Siyanova-Chanturia, A., Conklin, K., \& van Heuven, W. J. B. (2011). Seeing a phrase "time and again" matters: The role of phrasal frequency in the processing of multiword sequences. Journal of Experimental Psychology: Learning, Memory, and Cognition, advance online publication. doi: $10.1037 / \mathrm{a} 0022531$ 
Strik, H., Hulsbosch, M., \& Cucchiarini, C. (2010). Analyzing and identifying multiword expressions in spoken language. Language Resources and Evaluation, 44, 41-58.

Taylor, J. R. (2002). Cognitive grammar. Oxford, UK: Oxford University Press.

Tremblay, A., \& Baayen, H. (2010). Holistic processing of regular four-word sequences: A behavioral and ERP study of the effects of structure, frequency, and probability on immediate free recall. In D. Wood (Ed.), Perspectives on formulaic language: Acquisition and communication (pp. 151-173). London, UK: Continuum.

Tremblay, A., Derwing, B., Libben, G., \& Westbury, C. (2011). Processing advantages of lexical bundles: Evidence from self-paced reading and sentence recall tasks. Language Learning, 61, 569-613.

Trousdale, G., \& Hoffman, T. (Eds.). (2012). The Oxford handbook of construction grammar. Oxford, UK: Oxford University Press.

Tucker, G. (1996). So grammarians haven't the faintest idea: Reconciling lexis-oriented and grammar-oriented approaches to language. In R. Hasan, C. Cloran, \& K. Butt (Eds.), Functional descriptions: Theory in practice (pp. 145-178). Amsterdam, the Netherlands: John Benjamins.

Van Lancker, D. (1987). Nonpropositional speech: Neurolinguistic studies. In A. W. Ellis (Ed.), Progress in the psychology of language: Vol. 3 (pp. 49-118). Hillsdale, NJ: Erlbaum.

Van Lancker Sidtis, D. (2009). Formulaic and novel language in a "dual process" model of language competence: Evidence from surveys, speech samples, and schemata. In R. Corrigan, E. A. Moravcsik, H. Ouali, \& K. M. Wheatley (Eds.), Formulaic language: Vol. 2. Acquisition, loss, psychological reality, and functional explanations (pp. 445-470). Amsterdam, the Netherlands: John Benjamins.

Wierzbicka, A. (2009). Exploring English phraseology with two tools: NSM semantic methodology and Google. Journal of English Linguistics, 37, 101-129.

Wood, D. (Ed.). (2010). Perspectives on formulaic language: Acquisition and communication. London, UK: Continuum.

Wray, A. (1999). Formulaic language in learners and native speakers. Language Teaching, $32,213-231$.

Wray, A. (2000). Formulaic sequences in second language teaching: Principle and practice. Applied Linguistics, 21, 463-489.

Wray, A. (2002). Formulaic language and the lexicon. Cambridge, UK: Cambridge University Press.

Wray, A. (2008). Formulaic language: Pushing the boundaries. Oxford, UK: Oxford University Press.

Wray, A. (2010). We've had a wonderful, wonderful thing: Formulaic interaction when an expert has dementia. Dementia: The International Journal of Social Research and Practice, 9, 517-534.

Wray, A. (2011). Formulaic language as a barrier to effective communication with people with Alzheimer's disease. Canadian Modern Language Review, 67, 429-458.

Wray, A., \& Fitzpatrick, T. (2008). Why can't you just leave it alone? Deviations from memorized language as a gauge of nativelike competence. In F. Meunier \& S. Granger (Eds.), Phraseology in foreign language learning and teaching (pp. 123-148). Amsterdam, the Netherlands: John Benjamins.

Wray, A., \& Grace, G. W. (2007). The consequences of talking to strangers: Sociocultural influences on the lexical unit. Lingua, 117, 543-578.

Wray, A., \& Pegg, C. (2009). The effect of memorized learning on the writing scores of Chinese IELTS test takers. IELTS Report, 9, 191-216.

Wray, A., \& Perkins, M. R. (2000). The functions of formulaic language: An integrated model. Language \& Communication, 20, 1-28.

Wulff, S. (in press). Words and idioms. In G. Trousdale \& T. Hoffmann (Eds.), The Oxford handbook of construction grammar. Oxford, UK: Oxford University Press. Retrieved from http://www.lingtechcomm.unt.edu/ swulff/research/Wulff\%20\%28to\%20appear\%29. pdf 